\title{
Severe weather as a spectacle: the Meteo-Show
}

\author{
Iñaki Orbe ${ }^{1,2}$ and Santiago Gaztelumendi ${ }^{1,2}$ \\ ${ }^{1}$ Basque Meteorology Agency (EUSKALMET), Basque Country, Spain \\ ${ }^{2}$ Meteorology Area, Energy and Environment Division, TECNALIA R \& I, Basque Country, Spain \\ Correspondence to: Santiago Gaztelumendi (santiago.gaztelumendi@tecnalia.com)
}

Received: 13 January 2017 - Revised: 20 April 2017 - Accepted: 20 April 2017 - Published: 13 June 2017

\begin{abstract}
In this work we focus on perhaps one of the worst journalist practice when dealing with severe weather, the "Meteo-Show" or the extended practice, especially in TV, for using weather and meteorology for spectacle. Journalism today has found weather information in a real "goldmine" in terms of audience due to the growing public interest in this matter. However, as it happens with other content, sensationalism and exaggeration have also reached weather information, primarily when episodes of adverse nature (snow, heavy rain, floods, etc.) are addressed. In this paper we look to identify the worst practices in weather communication through analysis of examples from real journalist work. We present some keys to understand this trend, highlighting the ingredients that are present in the worst Meteo-show.
\end{abstract}

\section{Introduction}

The traditional media are undergoing a paradigm shift that is dictated by several societal, economic and technological factors. Proliferation of TV channels, during those last years, increases competence and triggers the fight for audience. In this context the necessity to attract viewers has caused a shift in the traditional way that information is transmitted in many Media, and especially in Television. Today, some degree of sensationalism, exaggeration and drama are often present in many TV programs, not only in entertainment or sports areas but also in news or weather. The aggressive and spectacular way to narrate events in TV is present since its beginnings in the 1950s, expanding progressively, and affecting today to all the globe, mainly associated with TV junk, reality shows and others manifestation of trash TV (e.g. Waisbord, 2004; Holmes and Jermyn, 2004; Hill, 2005; López and Bordodano, 2007; Murray and Ouellette, 2009; Kolker, 2009). Such practices, with a proven impact on audience shares (Hill, 2005), have been soon adopted in other fields, including the news. At the beginning, the live appearances were technically complex and expensive, so they were reserved just for interesting and relevant news. In that way, in-situ and live reports are supposed to reinforced the veracity of the information, transmitting rigor and allowing the professional to stress the importance of in-situ facts. Today, due to technological ad- vances among other reasons, live interventions are no longer reserved for first order events. The extended practice of TV live connections "just because we can" and some degree of sensationalist style in messages transmission are a pandemic present nearly everywhere on TV (e.g. Tuggle and Huffman, 1999, 2001; Tuggle et al., 2007; Fernández del Moral et al., 2009; Bronwyn, 2012; Mateos, 2013).

This practice soon had in the weather and climate one of his favourite arguments, and particularly during severe weather events. "Meteo-show" had been born. The real story regarding weather (based on professional forecast or observations) is replaced by a personal story, non-rigorous and sensationalist where journalist or reporter offers his opinions from a particular place supposedly affected by the effects of adverse weather.

\section{Methodology}

The authors, based on their daily relationship with the media as part of their professional activities in Euskalmet, analyse different journalistic practices regarding the treatment of severe weather information events on television, identifying common practices for "Meteo-show". The analysis and conclusions presented in this paper are based mainly in experiences affecting Basque Country and Spain. However during data recompilation and analysis we have detected same type 
of practices in other parts of the world. The authors have an extended professional baggage working for many years both in media and also in weather business.

\section{Discussion}

\subsection{The concept}

In this work we consider "Meteo-show" as any informative practice whose main objective is to increase audiences regardless of the veracity of the weather facts. "Meteo-show" doesn't provide useful information, though sometimes provide some data of some interest. Its main task is to transmit sensations to the public through dramatized, frivolous or exaggerated storytelling and dissemination of shocking images. In the "white" side still resist meticulous meteorological information transmitted by weather women and men (meteorologist or not, but always weather professionals), in the "dark" side there is the "Meteo-show" and in between the real world, always "gray".

\subsection{Key factors}

Different basic conditions are necessary in order to identify "Meteo-show" practices. Unless many of them must be present at same time in full extent "Meteo-show", more often than desirable, some of them are present under different circumstances in many weather programs.

\subsubsection{Live and on-site is always better}

The physical presence of a reporter in an area theoretically affected by some kind of weather adversity and reporting in a live connection is a must. The aim is to keep the informative tension and attention in the audience, regardless of what is happening and even if nothing serious take place.

\subsubsection{Interventions are dynamic and gestural}

The intervention tend to be dynamic and gestural, not much explanatory and not calm. On many occasions, reporters are forced to walk from one side to another, usually aimlessly, adding to his speech a forced and contrived gestural emphasis. The goal is to capture the attention of the audience maintaining forced suspense, often not corresponding to the real situation of this live intervention moment.

\subsubsection{The TV presenter is accomplice}

The presenter of the program abandons its more or less passive introducer/driver role and he became an active subject of the chronicle, encouraging and motivating the reporter in order to put the greater narrative and expressive emphasis on the anecdote. Focus is forced to aspects supposedly spectacular, and not to the real causes that have caused the episode. By this way, the presenter reinforces the show through a more or less frivolous dialogue between the two parties, usually focusing on dramatic anecdote and exaggeration of destructive effects.

\subsubsection{The reporter is the victim}

The reporter is forced to be part of the adverse event. That means that whenever the reporter is in an area particularly affected by severe rain, snow, wind, waves, etc. he or she should feel the effects in first hand. The journalist is obliged to be the protagonist of the story, suffering in their own the rigors of the environment, giving the feeling of being the victim of severe weather. Sometimes the forced situation becomes in a real risk to the integrity of the reporter. Often the goal of this practice is not to clarify aspects of severity, but just to transmit sensations to the viewer and to promote spectacle.

\subsubsection{The episode stretches on}

The message is transmitted with forced uncertainty, giving to the viewer the feeling that the episode has not ended, or will not end in the short term, although forecasts advertise for an imminent improvement. Or to transmit that the worst is by no means over, especially if impact is not enough spectacular or not according with what is delivered in former interventions. This message helps build loyalty to the audience and to create a false expectation in the public that will not hesitate to follow the weather information in the next live, regardless of whether a clear improvement occurs.

\subsubsection{The scenario can be fictitious}

If the scenario where intervention develops is not the desired, it is manipulated according to the interests of the message. These manipulations can be of different types, ranging from incorporating some forced element to the scene, to the change of location. The scene is forced to fit the message in order to accompany and reinforce the message that is intended to convey.

\subsubsection{The obvious is extraordinary}

It will always seek to place the adverse weather phenomenon within the category of extraordinary. Exaggeration in the degree of adversity seeks to capture the attention of the audience, making them believe that the episode is experiencing is not normal at all.

\subsubsection{Forcing the record and climate change link}

Instead of offering adjusted forecast and representative records, artificial, extraordinary or convoluted data are forced into record in order to support the spectacle, usually linking without any sense the particular severe weather episode with 
climatic change. Mass media loves headlines and key messages, numbers are supposed to transmit rigor and records reinforce the message and keep attention of the viewers.

\subsubsection{Live interviews aligned with predefined message}

Forced personal testimonies are used. Interviews and street side reports are conducted and aligned with the message by preselection of participants. Interviews to people supposedly affected by particular phenomenon contribute to strengthen and magnify the message that is intended to convey. According to their editorial lines, some TV channels employ this practice in order to amplify the criticism with the authorities. It seeks to reinforce messages through testimonies of ordinary people, causing empathy with the viewer and transmitting to the audience a false picture of reality.

\subsection{How meteorological agencies can respond to Meteo-show}

Although, in our opinion, the battle against the "Meteoshow" by the meteorological agencies is lost in advance, there are certain general guidelines that you should observe at least not to enhance these journalistic practices (e.g. Covello and Hallen, 1988; Hyer and Covello, 2005; Orbe, 2012; Gaztelumendi et al., 2016):

- Inform always, even anticipating the media requests.

- Develop press releases, with clear, understandable and simple statements.

- Promote pedagogy and disclosure.

- Be always reliable.

- Promote direct presence in the media to avoid wrong messages.

- Maximum collaboration, patience and continuous pedagogy with journalist.

- Understand the motivation, usually the reporter is not the responsible for mess, he/she has editors and heads back.

- Stay alert, television networks always watch each other, this phenomenon can be contagious.

\section{Conclusions}

In this paper we present some keys to identify "Meteoshow" practices in the context of TV programs, and what are the motivations behind these practices. The "Meteo-show" causes many negative effects on the meteorological community. The most important is the demotivation of the population in situations of real danger due to misinformation, the trivialization of messages and the spread of rumours. At the end, due to the usual journalist and viewer confusion regarding meteorological information sources, these practices may contribute to the disrepute of meteorological services.

Journalism today has found in weather information a real "goldmine" due to the growing public interest in this matter. Frivolity and spectacle have also reached weather information, primarily when episodes of adverse nature (snow, heavy rain, floods, etc.) are addressed. Although such practices are usually more common in morning or afternoon entertainment TV programs, they are also present in many weather news spaces, especially in such cases where time slots are expanded, more time is available for reports and best audiovisual technology is used to entertain the audience. One should not forget that weather services work for weather information (e.g. WMO, 2002, 2005), and that, although the media usually considers what meteorological services says, they generally modulate messages, in order to catch the attention of audiences for higher advertising revenue. Most of the TV channels have, in some degree, a tendency to "Meteoshow" (even public ones). So far, the meteorological agencies have no choice but to continue doing their job with maximum rigor and not forgetting the existence and extent of this phenomenon. Unfortunately no change is perceived in this TV tendency, fortunately new direct communication strategies based on social media (Twitter, etc.) are possible and recommendable (e.g. Wendling et al., 2013; Gaztelumendi et al., 2012, 2015, 2016).

Data availability. No data sets were used in this article.

Competing interests. The authors declare that they have no conflict of interest.

Acknowledgements. The authors would like to thank the Emergencies and Meteorology Directorate - Security Department - Basque Government for public provision of data and operational service financial support. We also would like to thank all our colleagues from EUSKALMET for their daily effort in promoting valuable services for the Basque community.

Edited by: T. Cegnar

Reviewed by: P. Giannopoulos and one anonymous referee

\section{References}

Bronwyn, E. B.: The media event: the future of television in New Zealand, New Zealand Journal of Media Studies, 13.2, 117-129, 2012.

Covello, V. and Allen, F.: Seven cardinal rules of risk communication, Washington, DC, U.S. EPA, Office of Policy Analysis, 1988.

Fernández del Moral, J., Quesada, M., Sánchez, J. J., and León, B.: Estudios de los informativos españoles de televisión de cobertura 
nacional, in: Transformar la televisión: otra televisión es posible, edited by: León, B., Comunicación social ediciones y publicaciones, 127-144, 2009.

Gaztelumendi, S., Egaña, J., Otxoa-de-Alda, K., Hernandez, R., Aranda, J., and Anitua, P.: An overview of a regional meteorology warning system, Adv. Sci. Res., 8, 157-166, https://doi.org/10.5194/asr-8-157-2012, 2012.

Gaztelumendi, S., Martija, M., Principe, O., and Palacio, V.: An overview of the use of Twitter in National Weather Services, Adv. Sci. Res., 12, 141-145, https://doi.org/10.5194/asr-12-141-2015, 2015.

Gaztelumendi, S., Orbe, I., Salazar, O., Lopez, A., Aranda, J. A., and Anitua, P.: Delivery and communication of severe weather events in Basque Country: the Euskalmet case, Adv. Sci. Res., 13, 87-90, https://doi.org/10.5194/asr-13-87-2016, 2016.

Hill, A.: Reality TV: Factual Entertainment and Television Audiences, 230 pp., Routledge, London and New York, 2005.

Holmes, S. and Jermyn, D.: Introduction: Understanding reality TV, in: Understanding reality television, edited by: Holmes, S. and Jermyn, D., 1-32, Routledge, New York, 2004.

Hyer, R. N. and Covello, V.: Effective Media Communication during Public Health Emergencies: A WHO Handbook, WHO/CDS/2005.31, Geneva, 2005.

Kolker, R.: The designs of media, in: Media Studies: An Introduction, edited by: Kolker, R., 11-41, Wiley-Blackwell, 2009.

Mateos, C.: El directo ético y el directo patético en los informativos de televisión, Comunicación y medios, no. 28, 61-79, Instituto de la Comunicación e Imagen, Universidad de Chile, 2013.

López, M. M. and Bordodano, J.: Telebasura, ética y derecho: límites a la información de sociedad en televisión, in: La ética y el derecho de la información en los tiempos del postperiodismo, 307-323, Fundación COSO, Valencia, 2007.
Murray, S. and Ouellette, L.: Introduction, in: Reality TV: Remaking television culture, edited by: Murray, S. and Ouellette, L., 1-20, New York University Press, 2009.

Orbe, I.: Emergencias y medios de comunicación, Publicación de academia vasca de policía y emergencias, Arkaute Akademia, Araba, 2012.

Tuggle, C. A. and Huffman, S.: Live news reporting: Professional judgment or technological pressure? A national survey of television news directors and senior reporters, J. Broadcast. Electron., 43, 492-505, 1999.

Tuggle, C. A. and Huffman, S.: Live Reporting in Television News: Breaking News or Black Holes?, J. Broadcast. Electron., 45, 335-344, 2001.

Tuggle, C. A., Huffman, S., and Rosengard, D. S.: Reporting Live From the Scene: Enough to Attract the 18-24 Audience?, J. Broadcast. Electron., 51, 58-72, 2007.

Waisbord, S.: Mc TV: Understanding the global popularity of television formats, Television \& New Media, 5, 359-383, 2004.

Wendling, C., Radisch, J., and Jacobzone, S.: The Use of Social Media in Risk and Crisis Communication, OECD Working Papers on Public Governance, No. 25, OECD, 2013.

WMO: Guide on Improving Public Understanding of and Response to Warnings, WMO/TD 1139, Geneva, Switzerland, 2002.

WMO: Guidelines on weather broadcasting and the use of radio for the delivery of weather information, WMO/TD1278, Geneva, Switzerland, 2005. 